ARTICLE

DOI: $10.1038 / s 41467-018-03187-y$

\title{
Spatial organization of bacterial populations in response to oxygen and carbon counter-gradients in pore networks
}

\author{
Benedict Borer ${ }^{1}$, Robin Tecon ${ }^{1} \&$ Dani Or (i) ${ }^{1}$
}

Microbial activity in soil is spatially heterogeneous often forming spatial hotspots that contribute disproportionally to biogeochemical processes. Evidence suggests that bacterial spatial organization contributes to the persistence of anoxic hotspots even in unsaturated soils. Such processes are difficult to observe in situ at the microscale, hence mechanisms and time scales relevant for bacterial spatial organization remain largely qualitative. Here we develop an experimental platform based on glass-etched micrometric pore networks that mimics resource gradients postulated in soil aggregates to observe spatial organization of fluorescently tagged aerobic and facultative anaerobic bacteria. Two initially intermixed bacterial species, Pseudomonas putida and Pseudomonas veronii, segregate into preferential regions promoted by opposing gradients of carbon and oxygen (such persistent coexistence is not possible in well-mixed cultures). The study provides quantitative visualization and modeling of bacterial spatial organization within aggregate-like hotspots, a key step towards developing a mechanistic representation of bacterial community organization in soil pores.

\footnotetext{
${ }^{1}$ Department of Environmental Systems Science, ETH Zürich, Universitätstrasse 16, 8092 Zürich, Switzerland. Correspondence and requests for materials should be addressed to B.B. (email: benedict.borer@usys.ethz.ch)
} 
S oil is a living and evolving ecosystem, hosting the greatest abundance and diversity of microbial life in the biosphere and serving numerous regulatory and provisional functions essential for life ${ }^{1,2}$. Microbes are at the core of soil ecological functioning; they drive key biogeochemical cycles of carbon and nitrogen, and regulate other fluxes important for plant function ${ }^{3}$. The dynamics, composition, and distribution of soil microbes are shaped by heterogeneous water and resource distribution, and by their ability to rapidly adapt to dynamic changes in local conditions ${ }^{4}$. These intricate local interactions give rise to dense biological hotspots ${ }^{5}$ that often coincide with nutrient-rich zones such as the rhizosphere ${ }^{6,7}$, detritusphere ${ }^{8}$, biopores ${ }^{9-11}$, and soil aggregates ${ }^{5,12-14}$. Microbial activity in hotspots accounts for a large portion of soil biogeochemical fluxes, for example, the production of nitrous oxide within a soil core is dominated by denitrification hotspots in which $1 \%$ of the soil volume may account for up to $90 \%$ of the denitrification activity ${ }^{15}$. The localized and intense microbial activity within small soil volumes gives rise to the formation of anoxic regions. Diffusing oxygen is consumed directly at the periphery of such hotspots ${ }^{16,17}$, which in turn promotes segregation of aerobes and anaerobes within the local soil microbial community ${ }^{18}$. This spatial organization of bacterial cells combined with high density of microbial activity promotes and sustains anoxic zones even in aerated soils ${ }^{19}$, for example, in drained rice paddy soils ${ }^{20}$ or within the rhizosphere ${ }^{17}$. Soil aggregates have received considerable attention in the past ${ }^{14}$, concerning their internal chemical conditions ${ }^{16,21}$, and the distributions of carbon ${ }^{22,23}$ and bacterial communities ${ }^{24-26}$.

The formation of microbial community spatial patterns at relevant (micro)scale has been studied over the past decades, with several recent mechanistic models ${ }^{27-30}$ and experiments ${ }^{31-35}$, highlighting the importance of spatial organization processes and functional implications ${ }^{26}$. Here, spatial organization represents the emergence of microbial community patterns that stem from local interactions ${ }^{36}$. These recent studies have hinted at key factors that promote spatial organization of microbial consortia, including (but not limited to) nutrient spatial gradients, trophic dependencies, and chemotactic cellular motility ${ }^{37}$. Evidence suggests that microbial communities within soil aggregates spatially organize in response to diffusion in three-dimensional pore networks with biologically mediated oxygen gradients ${ }^{16,21}$. The potential role of persistent and opposing gradients (hereafter counter-gradients) of oxygen and carbon on microbial function has been demonstrated experimentally by glucose perfusion (aimed to disrupt established carbon gradients) with marked changes in microbial activity for different aggregate sizes ${ }^{24}$. These observations are supported by studies of microbial community composition that show organized species distribution at the pore scale $25,38,39$. Despite the importance of such microscale spatial organization processes, evidence of bacterial organization in soil pores remains elusive due to the opaque nature of soil particles and difficulties of in situ visualization. Stable spatial patterns of microbes can emerge from an initially homogeneously distributed community as the result of differential growth within a heterogeneous habitat. Studies documenting microbial community patterns in soil often do not discriminate between spatial organization driven by cell motility or by preferential growth and cell division, owing to the lack of control over initial microbial distributions ${ }^{25,31,40-43}$. Yet, such a distinction is of paramount importance for the temporal dynamics of bacterial hotspots, especially considering the highly dynamic and episodic wetting of soil (and establishment of nutrient gradients).

Notwithstanding the growing number of observations from field studies, the inherent diversity and complexity of soil microbial life in a multifaceted environment remain entangled and limits systematic hypotheses testing of biophysical processes and validation of mathematical models. To overcome these limitations, we propose to investigate a well-characterized microbial community in simple and reproducible artificial systems that nevertheless capture salient features of the soil habitat. Although significantly simplifying, the full scope of soil-microbe complexity, such a bottom-up approach, permits isolation of certain key soil physicochemical components, making them amenable for systematic investigation towards extracting general principles for microbial organization in soil pores.

The hypothesis is that bacterial communities composed of members with different metabolic capabilities (and trophic preferences) that reside within a structured environment (pore networks) would spatially organize over time in response to nutrient counter-gradients. To study basic aspects of bacterial community spatial organization, we have developed an experimental platform that retains essential features that develop in soil aggregates: water-filled micrometric pore networks that supports persistent counter-gradients of carbon and oxygen. The system is comprised of sealed glass-etched pore networks with access at five locations (ports). A mathematical model of the experimental system was developed to interpret and gain insights into the experimental results. The model combines numerical nutrient diffusion with an individual-based representation of bacterial cells and enabled us to simulate scenarios that were impossible to create within the experimental model system such as ubiquitous oxygen. We selected a model bacterial community composed of an obligate aerobe and a facultative anaerobe, both able to disperse by swimming motility and to colonize the pore networks. The study aimed to document counter-gradient induced soil bacterial spatial organization in action, by direct visualization in pore networks and by mechanistic modeling of key processes. We have shown that aerobic and anaerobic bacterial populations spontaneously segregated in response to pore geometry and nutrient gradients. Counter-gradients of oxygen and carbon were necessary and sufficient for the resulting segregation, as demonstrated by experiments and simulations. We demonstrated that while a structured habitat with gradients promoted the stable coexistence of the two bacterial species, their growth in well-mixed habitats led to the competitive exclusion of one of the species.

\section{Results}

Pore networks to study organization of bacterial populations. The experimental set-up, consisting of micrometric pore networks etched in glass, was designed to allow control of physicochemical conditions and observation by microscopy (Fig. 1). The network of $200 \mu \mathrm{m} \times 40 \mu \mathrm{m} \times 15 \mu \mathrm{m}(L \times W \times H)$ rectangular channels (bonds) permits flagellated rod-shaped bacteria to freely disperse in the pore network by means of swimming motility. The pore network was saturated with aqueous medium (modified M9 minimal medium, see Methods) that inhibited oxygen gas diffusion while enabling rapid diffusion of solutes (carbon and nitrogen compounds). Five ports allowed access to the otherwise hermetically sealed channel network to impose boundary conditions mimicking resource architectures postulated for carboncentered hotspots such as soil aggregates (Fig. 2). The model pore network facilitates observation and quantification of bacterial spatial organization as a function of network geometry and resource gradients.

The pore networks architecture was varied to represent different degrees of pore connectivity that would alter diffusional and cell dispersion pathways (resembling aqueous habitat fragmentation in unsaturated soil). A fully connected network (each junction/node is connected to six channels) was progressively disconnected by random deletion of channels while maintaining backbone connectivity (i.e., each channel of the 


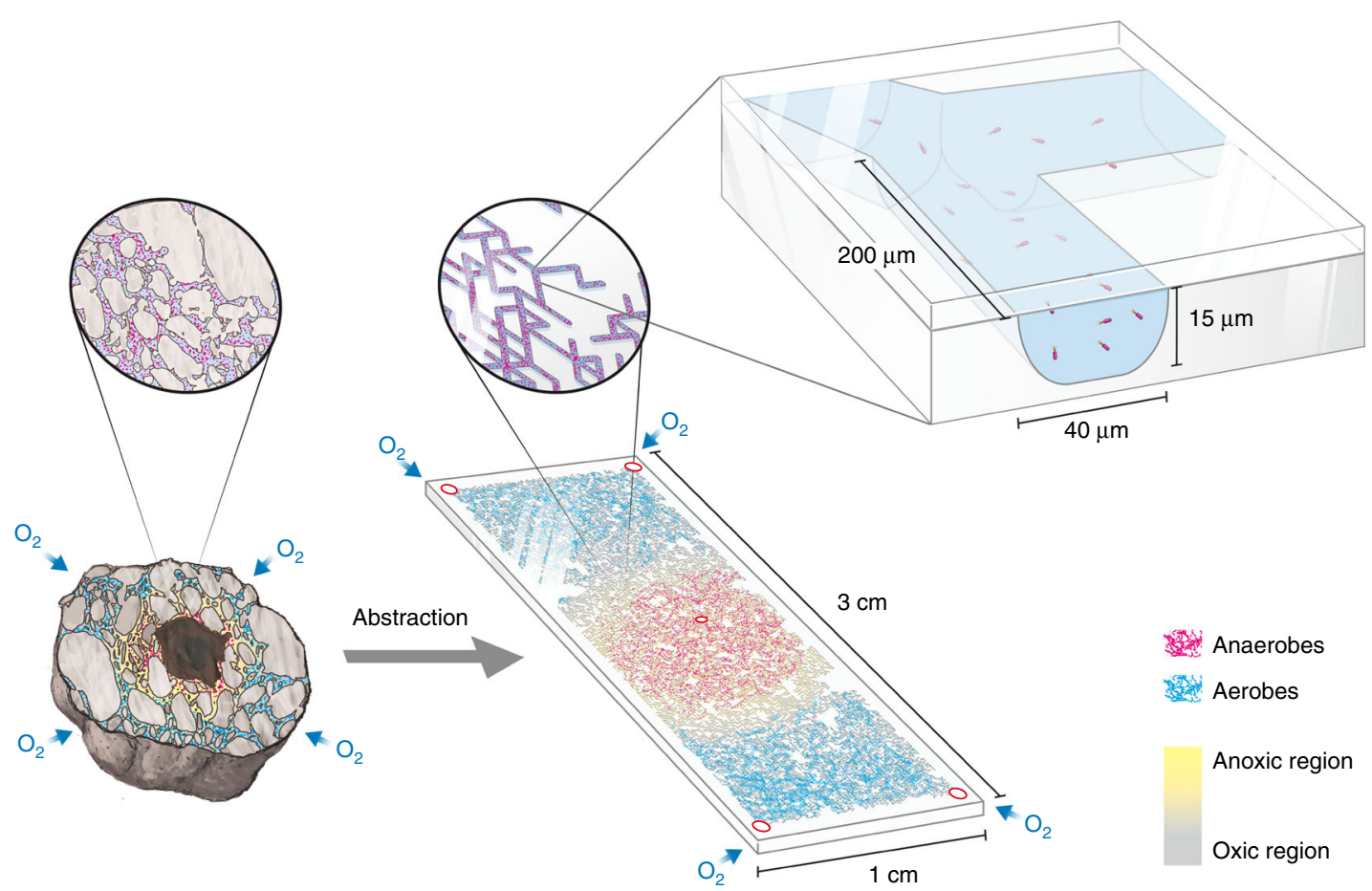

Fig. 1 Conceptual view of a model pore network. Aerobes (blue) and anaerobes (red) spatially segregate in a natural soil aggregate due to anoxic conditions at the core (illustrating a central carbon source and oxygen diffusing from the aggregate outer surface). Glass-etched micrometric 2-D pore networks mimicking an idealized cross-section in a soil aggregate were used in the experiments. Chemical boundary conditions similar to those postulated for saturated soil aggregates within an unsaturated soil were imposed via 5 ports allowing access to an otherwise sealed pore network. The pore network geometry allows nutrient diffusion through saturated pores and ample space for bacterial flagellated motility. The emerging spatial self-organization of the two microbial species due to opposing nutrient sources and locally modified gradients can be directly visualized and quantified using fluorescence microscopy through the transparent glass walls

network is accessible from every location within the network) (Fig. 2). We expected that regions in the pore network would become anoxic due to the combined effects of low oxygen diffusion via saturated pores and oxygen consumption by (aerobic) bacteria.

The experiments were guided by a mathematical model that combined nutrient diffusion with an individual-based representation of bacterial cells ${ }^{30,44-46}$. The spatial characteristics of the experimental pore networks were reproduced in the mathematical model for scenario generation. Bacterial cells were represented in the model by motile agents capable of chemotactic motion in response to nutrient and oxygen gradients ${ }^{30,47}$. The individual agents (bacterial cells) interacted with their chemical environment by sensing and consuming local nutrients and were attracted or repelled by oxygen concentrations. The virtual bacteria grew following Monod kinetics; locally adjustable growth rates, and the ability to divide or deplete internal energy and die were represented (see Methods for details of the model) ${ }^{30,44,48-50}$. Nutrient boundary conditions within the mathematical model are congruent to the respective experimental scenario. Additionally, different scenarios such as neglecting chemotaxis or removing nutrient gradients were simulated to identify key factors governing spatial organization of the model community in silico.

For the experiments, we have used two motile bacterial species isolated from soil, an obligate aerobe Pseudomonas putida and a facultative anaerobe Pseudomonas veronii, as the model community. The two species were tagged with autofluorescent proteins (using a green and a red fluorescent protein for $P$. putida and $P$. veronii, respectively) to permit their identification and distribution in the pore network. The formation of stable spatial bacterial community patterns, in response to the arrangement of carbon and oxygen resources, were quantified from digital image analyses of fluorescence microscopy images. The two species were simulated in the mathematical model as an obligate aerobe and an obligate anaerobe. $P$. veronii was represented as obligate anaerobe due to limitations of modeling facultative anaerobes using simple growth kinetics. For simplicity, $P$. putida and $P$. veronii are further referred to as (obligate) aerobes and (facultative) anaerobes, respectively.

Counter-gradients drive segregation of bacterial populations. Prior to bacterial inoculation, the pore networks were saturated with modified M9 minimal devoid of citrate overnight under vacuum. An intermixed community containing a 1:1 ratio of aerobes to facultative anaerobes was inoculated by pipetting at the central port (Fig. 2), which was subsequently sealed using an agar plug containing a high concentration of citrate (carbon and energy source) and nitrate (electron acceptor for anaerobic respiration), and finally capped with silicone to prevent oxygen diffusing into the port. After seven days of incubation at room temperature $\left(\sim 23^{\circ} \mathrm{C}\right)$, the distribution of the two species within the pore networks was imaged using a fluorescence microscope (Fig. 3). Image analysis tools were used to locate bacterial cells within the microscopy tile scans and consequently mapped onto the pore network for direct comparison with model predictions. This step of mapping bacterial cells onto the network also enables their distribution to be related to network properties such as the shortest path distance (Supplementary Fig. 1), which is important since diffusion within the network follows the shortest paths (irrespective of Euclidean distances). The spatial distribution of the two bacterial species along the shortest path from the central to peripheral ports, including predictions from the mathematical model, is shown in Fig. 4. 
$30 \mathrm{~mm}$

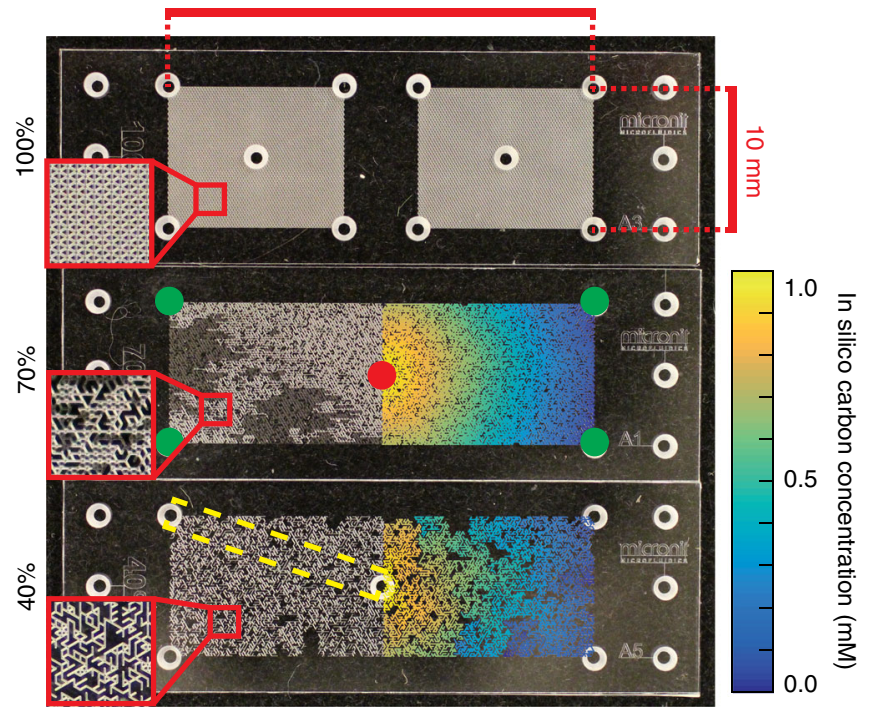

- Example orientation of microscopy tile scan

Central port Peripheral ports

Fig. 2 Images of the micrometric pore networks with varying levels of pore connectivity. The pore network connectivity was systematically reduced by randomly deleting channels (30\% and $60 \%$ of the channels deleted in the $70 \%$ and $40 \%$ lattices, respectively) while ensuring that the network remains connected (maintains percolation across opposing sides). Four peripheral ports and one central port allow access to the otherwise hermetically sealed network. Overlaid colored networks show in silico simulated carbon gradients emerging 1 day after bacterial growth with carbon source in the central port and peripheral oxygen (with aerobes and anaerobes present in the network). The network geometry exerts a significant influence on network-wide concentration fields as shown with the overlaid carbon concentration. Microscopy images of the glass-etched micromodels with inoculated bacterial cells were taken from the central to a peripheral port (dashed yellow rectangle)
While chemical gradients within the network were not observable in these studies, we verified the onset of oxygen gradients within the network using oxygen optodes ${ }^{51,52}$. Results confirmed the presence of anoxic conditions at the central port, and of oxic conditions at peripheral ports (in contact with atmospheric oxygen) (Supplementary Fig. 2). A control experiment with a network containing no bacterial cells confirmed persistent oxic conditions at all five ports (Supplementary Fig. 2), indicating that the presence of anoxic conditions at the center of the pore network was induced by bacterial respiration.

For all three lattice connectivity designs considered here (Fig. 2), the facultative anaerobes dominated the central region of the pore network (close to the carbon source) at the end of the incubation period (Figs. 3 and 4). Clearly distinguished patterns of spatial segregation of the two bacterial populations were visible within the $100 \%$ and $70 \%$ connectivity lattices with obligate aerobes residing closer to the peripheral ports (Figs. 3 and $4 a, b$ ). The segregation pattern was somewhat obscured within the $40 \%$ lattice (Fig. 4c). The mathematical model captured salient features of the observed spatial segregation (between aerobes and anaerobes) for the different connectivity pore networks, although the position of maximal aerobe proliferation was predicted closer to the peripheral ports than observed (Fig. 4). In the pore networks of highest connectivity (100\% lattice, Fig. 2), a subpopulation of facultative anaerobes was experimentally observed close to the peripheral port with a mean magnitude comparable to that of the obligate aerobes, while the mathematical model predicted only aerobes at this position (Fig. 4a). The size of the aerobic population close to the peripheral port was much smaller in the pore network with intermediate connectivity (70\% lattice, Fig. 2) compared to the $100 \%$ lattice, and no secondary population of facultative anaerobes was observed. In line with the experimental results, the mathematical model predicted a comparable segregation of aerobes and anaerobes (Fig. 4b) with obligate aerobes closer to the peripheral port. The spatial pattern within the lowest connectivity lattice was less obvious due to network structural heterogeneity and localization of aerobic cells within the network (Fig. 4c). More specifically, each imaging transect covered multiple regions of the network,

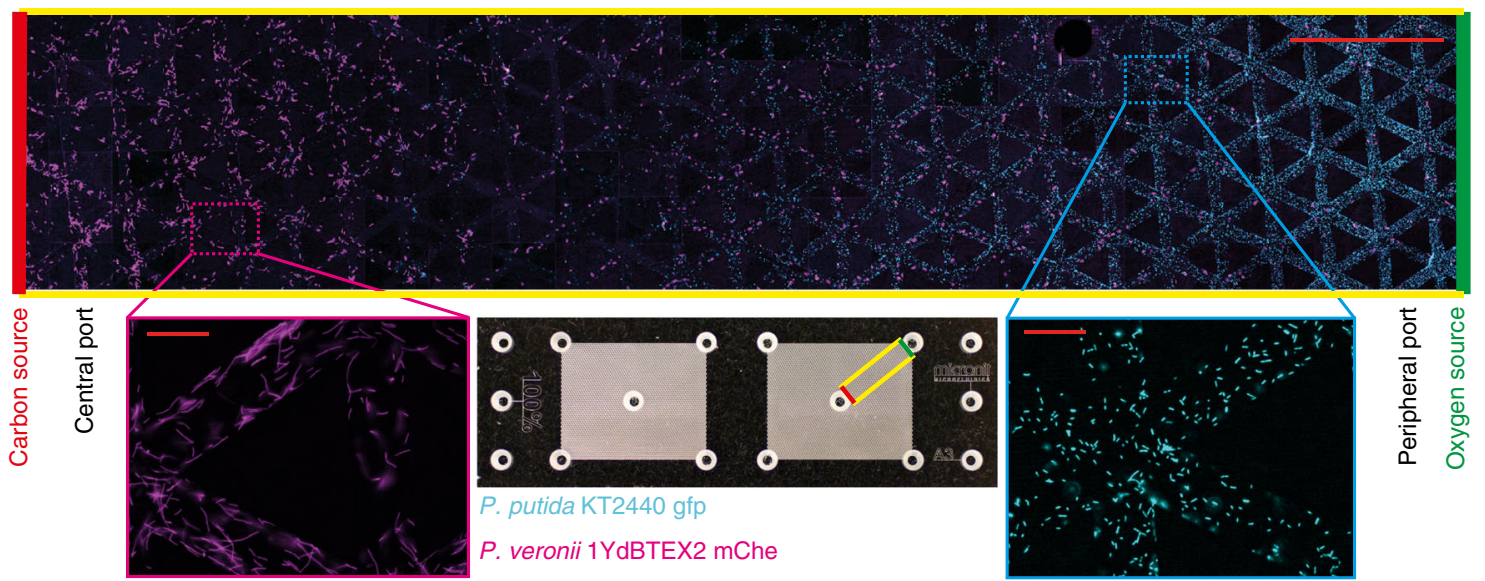

Fig. 3 Experimentally observed spatial segregation of bacterial populations in a micrometric pore network. The facultative anaerobic Pseudomonas veronii strain 1YdBTEX2-mChe is tagged with the mCherry fluorescent protein and shown with pseudo-color magenta, and the obligate aerobic Pseudomonas putida strain KT2440-gfp is tagged with the eGFP fluorescent protein and shown with pseudo-color cyan. The two species were mixed 1:1 in suspension and inoculated to the central port (total of $\approx 500$ cells per species) of a pore network with a carbon source (citrate) located at the center and oxygen diffusing from the peripheral ports. Both species were able to disperse through the pore network by flagellated motility. The exemplary overlay fluorescence image (top) shows the distribution of the two bacterial populations in a transect across the 100\% connected pore network (see inset) 1 week after inoculation (image contrast and brightness were enhanced for better visualization of the bacterial populations). The scale bar represents $500 \mu \mathrm{m}$. The two close-up images show individual bacterial cells within one microscopy image, as used for digital image analysis and cell counting (each scale bar represents $40 \mu \mathrm{m}$ ) 

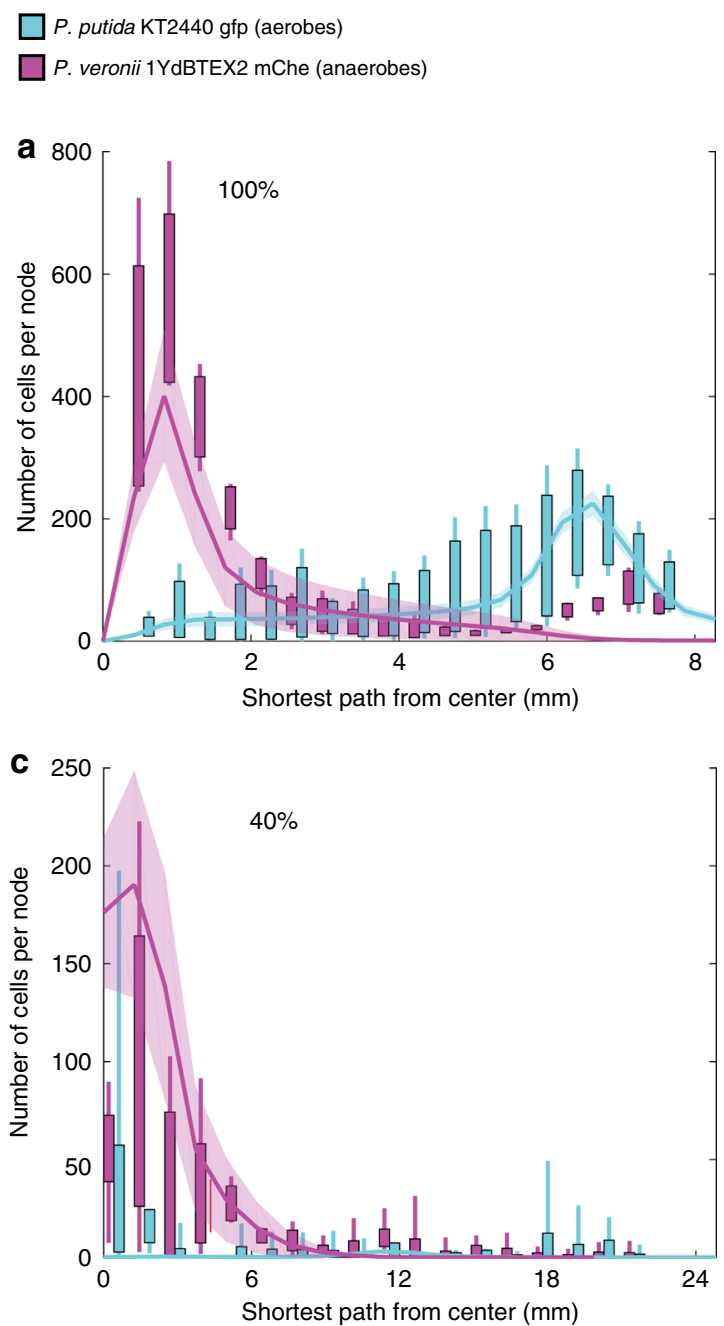
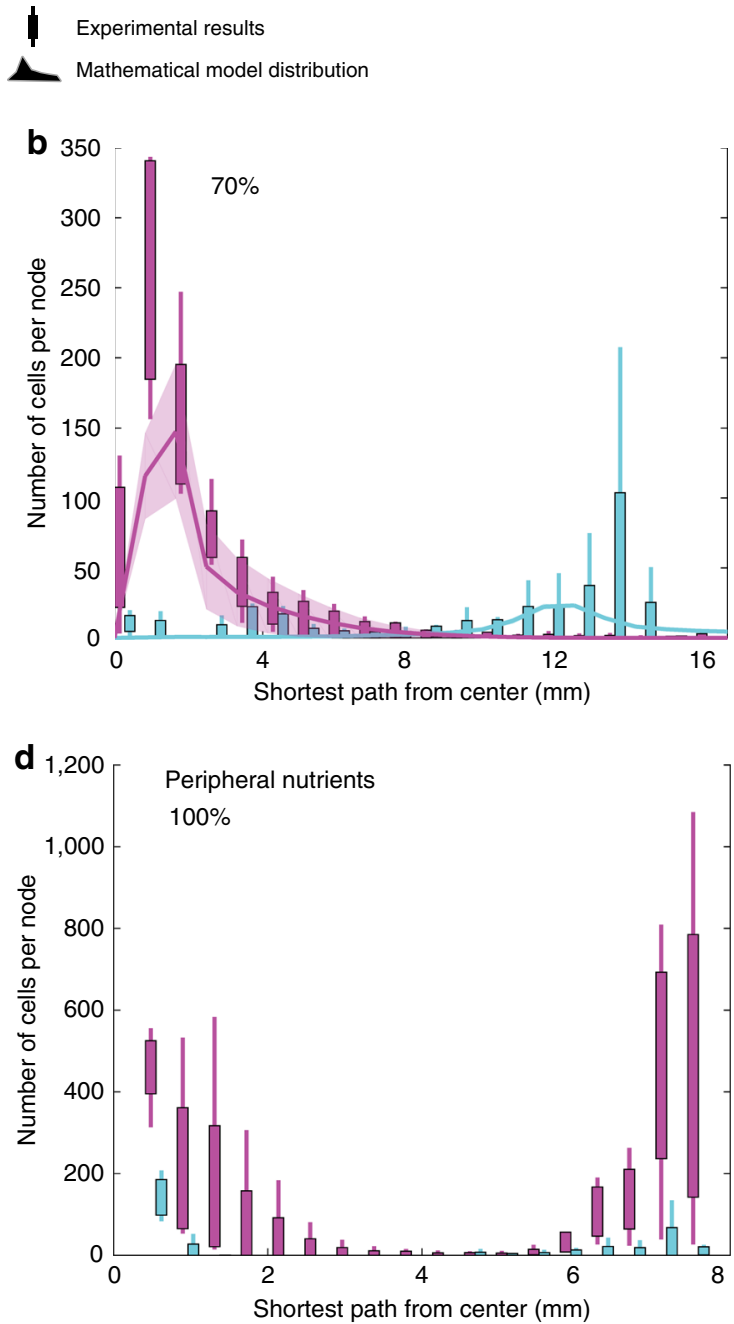

Fig. 4 Distribution of aerobes and anaerobes as a function of spatial positioning within the different pore networks. Results show combined experimental cell distribution and simulation results from the mathematical model for all pore network connectivities (a-c), using counter-gradients of citrate (maximum concentration at center port) and oxygen (maximum concentration at peripheral ports). Experimental results are represented in boxplots (whiskers indicate minimum to maximum value of data) of three, four, and five experimental replicates for the $100 \%, 70 \%$, and $40 \%$ pore networks, respectively. In the mathematical model results, thick line indicates the mean and shaded area includes $95 \%$ of all cells. In the experiments, bacterial cells in fluorescence microscopy images were identified using digital image analysis, mapped onto the pore network, and attributed to the closest nodes. These were subsequently grouped into bins with respect to their shortest path from the central port. A pore-scale segregation of the two species is visible within each connectivity. In the $40 \%$ lattice, the distribution is less clear due to perturbations of the pore network geometry. To test the role of counter-gradients, the experimental results in $\mathbf{d}$ depict bacterial distributions for carbon and oxygen collocated at the peripheral ports (eliminating counter-gradients) resulting in dominance of facultative anaerobes at both the central and peripheral ports. Simulations of this scenario would result in the dominance of aerobes at the peripheral port due to the (simplified) representation of $P$. veronii as an obligate anaerobe

some of which were more or less connected to each other, resulting in patchy distributions. The mathematical model captured the ratio of anaerobic to aerobic population size well, but predicted a more defined peak of anaerobic cells than was shown in the experimental results (Fig. 4c). A significant reduction in total bacterial cell density (two-sample $t$ test, twotailed) is observed with decreasing network connectivity ( $p$ values of 0.044 and 0.028 when comparing the fully connected network to the $70 \%$ connectivity lattice and the latter with the $40 \%$ connectivity lattice, respectively). The same comparisons based on the mathematical model results are highly significant with $p$ values of $9.82 \times 10^{-10}$ and $1.75 \times 10^{-5}$. Biomass differences within the mathematical model are more significant due to the higher number of numerical realizations compared to the number of experimental replicates. We conducted a verification experiment to confirm that the observed spatial organization was due to the opposing carbon and oxygen gradients using a fully connected lattice with collocated oxygen and carbon sources at the peripheral ports while bacterial cells were introduced via the central port. The facultative anaerobe $P$. veronii dominated both the central and peripheral ports in the collocated scenario (Fig. 4d). Despite the higher growth rate of obligate aerobic species in fully oxic environments, the initial conditions within the network (anaerobic-limited or oxygen diffusion-limited conditions) favored the facultative anaerobes, giving them a competitive edge during the early stage of community establishment, thus enabling them to outcompete the obligate aerobic species even at the periphery.

In addition to the experimental results, model simulations have been used to study how previously identified factors (chemotactic behavior, cell motility, resource gradients, and metabolic preferences ${ }^{28}$ ) govern bacterial spatial organization at the pore 


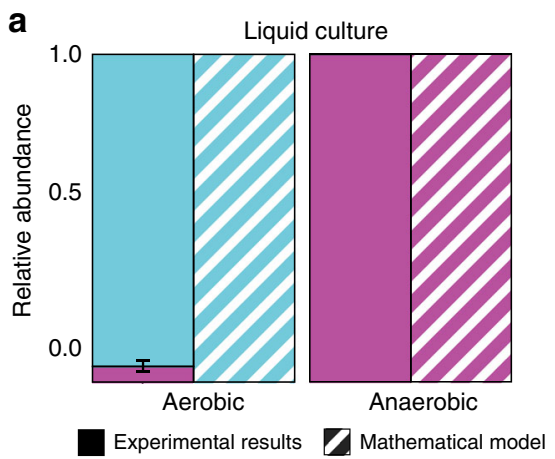

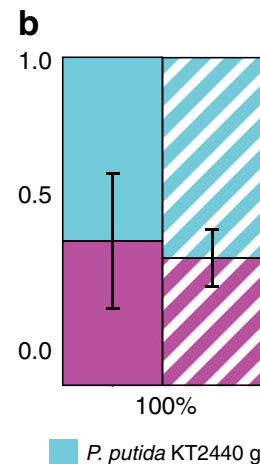

$100 \%$

putida KT2440 gfp (aerobe)
Pore network models

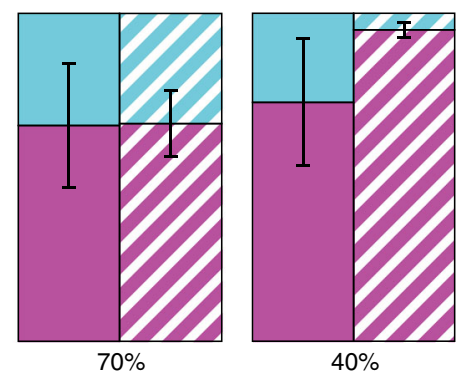

P. veronii 1YdBTEX2 mCher (anaerobe)

Fig. 5 Relative abundance of the two species in the community as a function of growth conditions and spatial structure of the environment. a Aerobes and facultative anaerobes were cocultured in shaken liquid medium to create an unstructured environment. A 1:1 ratio of aerobes to anaerobes was used to inoculate sealed serum flasks (to promote anaerobic respiration) or test tubes (aerobic respiration). After $72 \mathrm{~h}$ of incubation, culture samples were plated on selective agar media to determine the ratio of aerobes and anaerobes. Error bars show one standard deviation around the mean calculated from ten replicate cultures. Simulations represented a fully oxic and fully anoxic environment for the aerobic and anaerobic conditions, respectively. b Relative abundance of aerobes and anaerobes in pore networks calculated from results presented in Fig. 4a-c using counter-gradients (central carbon and peripheral oxygen). Error bars represent one standard deviation around the mean calculated from eight model realizations for mathematical results and three, four and five replicates for the experimental results in the $100 \%, 70 \%$ and $40 \%$ connectivity, respectively. In well-mixed environments represented as liquid flasks, very limited coexistence (aerobic conditions) or absence of coexistence (anaerobic conditions) were observed with dominance of obligate aerobes in the aerobic case and vice versa for the anaerobic case (a). Coexistence was facilitated due to the structured environment and resulting porescale segregation of the two species (b)

scale. The main aim of these simulations was to obtain bacterial distributions for scenarios that could not be easily tested in the experimental pore networks. These included the omission of cell chemotactic behavior and prevention of substrate gradients within the network. Both of these scenarios resulted in a uniform distribution of bacterial cells along the shortest path from the center to the periphery, as shown in Supplementary Fig. 3.

Segregation favors coexistence of competing species. Our experiments demonstrated that competing bacterial populations of aerobes and (facultative) anaerobes attained a state of stable coexistence, suggesting an important role of spatial segregation within pore networks (that limit nutrient diffusion pathways) in promoting such coexistence. We examined the question of whether aerobes and facultative anaerobes would also coexist in the absence of a spatially structured environment (pores or channels) and in the absence of nutrient gradients. We inoculated the two species in sealed serum flasks containing liquid medium for anaerobic growth conditions. In both, experimental and simulation results, the obligate aerobes clearly dominated the community under aerated growth conditions (95\% of total population), while conversely the facultative anaerobes prevailed under anoxic conditions (99.9\%) (Fig. 5a). These results contrasted strikingly with the coexistence observed in micrometric pore networks (Fig. 5b), where a reduction in connectivity increases the relative abundance of facultative anaerobes within the community $(39 \pm$ $21 \%, 66 \pm 19 \%$, and $95 \pm 19 \%$ of the community were anaerobes for the $100 \%, 70 \%$, and $40 \%$ lattices, respectively), which was mainly due to a decrease in obligate aerobes. The mathematical model captured these characteristics reasonably well, although it predicted lower relative abundance of obligate aerobes compared to the experimental results (Fig. 5b). Furthermore, additional pore network geometries were created to systematically evaluate interactions between network connectivity and relative abundance of the two species using the individual-based model (see Supplementary Fig. 4). The main effect of network connectivity stems from a reduction in network diffusivity that translates to lower biomass for the aerobic species (as they rely on carbon diffusing from the core) while the obligate anaerobe benefits from collocated sources, resulting in a gradual shift in relative abundance.

\section{Discussion}

This study reports visualization and quantification of spatial organization of a two-member bacterial community in pore networks mimicking the architecture and nutrient gradients postulated in carbon-centered hotspots such as soil aggregates (i.e., a carbon-rich anoxic core and oxic exterior boundaries) (Figs. 1 and 2). The experiments and model simulations were used to test the hypothesis that nutrient counter-gradients and cell motility within pores were necessary and sufficient conditions for the spatial organization and stable coexistence of bacterial species with different respiratory metabolisms.

The two species were able to disperse and grow in the pore networks, coexisting as largely spatially segregated populations with the facultative anaerobes dominating the carbon-rich and anoxic central region and aerobes prevailing in the well-aerated peripheral regions (Figs. 3-5). In agreement with observations (Supplementary Fig. 2), the mathematical model predicted that bacterial aerobic respiration would rapidly deplete oxygen concentrations in the pore network, resulting in an oxygen gradient from the oxic exterior to the mostly anoxic central region dominated by anaerobes (Fig. 4 and Supplementary Fig. 5). However, the oxygen gradient was not sufficient to maintain the segregation of aerobes and anaerobes: the presence of a carbon (citrate) counter-gradient (i.e., high in the center and low at the periphery) was also required (Fig. 4). Additional simulations were performed to confirm the necessity of gradients for spatial organization and coexistence of the two species. Complete removal of gradients within the networks was infeasible experimentally since bacterial communities self-engineer their environment through consumption of nutrients. Removing nutrient gradients in the mathematical model (by homogenizing the network with nutrients at each time step) resulted in a uniform distribution of aerobes and anaerobes (Supplementary Fig. 3). These results underline the importance of oxygen-carbon counter-gradients for spatial organization of aerobic and anaerobic populations, which was previously posited for microbial 
organization in soil aggregates ${ }^{16,53}$. The glass pore networks mimicking soil aggregate cross-sections were used in this study as a proxy for microbial hotspots where counter-gradients emerge due to spatially isolated nutrient sources. This architecture is not unique to soil aggregates, but is commonly found in soil; for instance, within the rhizosphere (rhizodeposits as carbon source) ${ }^{54}$ or detritusphere (dead root matter/fungi) ${ }^{5}$. Such counter-gradients have also been documented within the diffusive regime of marine snow particles during nighttime, when oxygen production by photosynthesis ceases ${ }^{55}$.

To test how pore network topology and the resulting diffusional landscape affect bacterial organization, we varied the aqueous connectivity in the network from a homogeneous lattice $(100 \%)$ to a heterogeneous and poorly connected lattice (40\%) (Fig. 2). Total bacterial abundance decreased with a reduction of pore network connectivity (Figs. 3 and 4), suggesting sensitivity to diminishing carbon fluxes due to fragmented and tortuous diffusive pathways. Similarly, the mathematical model predicted lower total carbon fluxes from the central port to the periphery with decreasing pore network connectivity (Fig. 2 and Supplementary Fig. 5). Decreasing pore network connectivity modifies and obscures the pattern of aerobe and anaerobe segregation (Fig. 4). Low connectivity (40\%) resulted in a patchy distribution of aerobes along the shortest path from the center in both experiments and model simulations. We could not ascertain whether the aerobes observed near the central region in the low connectivity network of the experiment were active or dormant (pores are inaccessible for direct sampling). However, since $P$. putida is an obligate aerobe and the pore network's core was mostly anoxic as mentioned above, we surmise that the remaining aerobic cells at the central port were metabolically inactive. Overall, the results showed how the change in diffusional landscape dictated by the connecting aqueous phase affects bacterial spatial organization.

In the absence of bacterial activity, molecular diffusion would mix and dissipate nutrient counter-gradients over time (days in our system) (Supplementary Fig. 2). Moreover, the formation and maintenance of oxygen gradients by bacterial respiration created new niches that could be exploited by the facultative anaerobes in the pore network (Fig. 4), whereas under fully oxic conditions the anaerobic population waned (Fig. 5). The observation in the model micrometric pore network thus represents an interesting case of bacterial niche engineering ${ }^{56}$ similar to a mechanism postulated to sustain anoxic hotspots in soils ${ }^{16}$. Additionally, the microhabitats facilitated by the pore network conferred coexistence of the two bacterial species (Figs. 3 and 4) compared to well-mixed flasks (where gradients are mostly absent) that lead to species competitive exclusion (Fig. 5). This demonstrated that the results of interspecific interactions were modified in the micrometric pore network in comparison to flasks. These observations illustrate the crucial role of structured habitats for the stability of microbial communities 57 .

In the experiments, anaerobes were able to colonize regions near the aerated ports in the fully connected (100\%) network (Fig. 4), where diffusional carbon fluxes from the center to the periphery were substantial (large number of diffusive pathways and shorter diffusion lengths). The pattern was different than predicted by the mathematical model which assumed that the virtual obligate anaerobes would be inhibited by oxygen. The model could be expanded to consider facultative anaerobes using different growth kinetic expressions such as switching metabolism (between aerobic and anaerobic ${ }^{49}$ ). Such adaptation would influence the distribution of the facultative anaerobes and relative abundance of the two species while the underlying nutrient landscape would remain as dictated by the network connectivity (see Supplementary Fig. 6). We opted for the more parsimonious model where facultative anaerobes are represented as obligate anaerobes for simplicity as it captures the primary mechanisms that give rise to spatial segregation and coexistence of the two species reasonably well.

An important ingredient for the spatial organization of the community (in addition to counter-gradients, trophic preferences, and connectivity) is bacterial chemotactic motility. Since the mixed inoculum was introduced at the center of the network, aerobes had to traverse the network towards the peripheral ports to establish subpopulations in the oxic regions. Previous studies have demonstrated the motile behavior ${ }^{58}$ and aerotaxis ${ }^{59}$ of aerobic $P$. putida as well as motility of $P$. veronii ${ }^{60}$. Chemotaxis is important for the rate of spatial organization, where bacterial cells may traverse distances orders of magnitude faster than in the absence of chemotactic-guided motility ${ }^{50}$. Importantly, the mathematical model predicted no spatial segregation in the absence of chemotaxis and aerotaxis during periods comparable to the incubation of the experiments (Supplementary Fig. 3). These findings are consistent with theoretical studies that have identified trophic preferences, persistent nutrient gradients, and motility as factors promoting spatial organization of bacterial communities $^{28}$. Trophic preferences are reflected by the segregation of the two species into two subpopulations where facultative anaerobes obtain a metabolic advantage in the anoxic core $^{18}$. Evidence suggests that the observed organization required active migration by flagellated motion and subsequent population growth. Alternate modes such as directed cell division and passive cell diffusion would be too slow to produce the observed spatial pattern within the time frame of the experiments. This suggests that gradient-guided cell motility was an important ingredient in achieving the spatial distribution observed in our experiments.

For simplicity, we have varied aqueous phase connectivity by removing bonds (Fig. 2). In soil environments, changes in aqueous phase connectivity would be influenced by the onset of unsaturated conditions during wetting and drying cycles ${ }^{4}$ (fully saturated pore networks such as $100 \%$ lattice would be short lived). Such transients do not preclude bacterial spatial organization, as these are relatively rapid processes (hours) as the study has shown, a time frame comparable to the duration of very wet soil conditions following rainfall or irrigation. Furthermore, microorganisms can modify the local hydraulic properties of unsaturated soil, by colonizing pore surfaces ${ }^{61}$ or via the production of extracellular polymeric substances ${ }^{62}$. Such modifications may influence drainage and drying characteristics of pore spaces $^{63}$ and prolong favorable conditions for bacterial spatial organization in such hot spots.

In conclusion, the experimental and mathematical models developed in this study successfully identified basic biophysical factors that exert control over bacterial spatial organization and that can be related to natural features found in soil environments. The models allowed us to systematically study some of the prime factors that give rise and facilitate bacterial community spatial organization at the pore scale, hence confirming findings of previous theoretical ${ }^{28,64}$ and experimental studies ${ }^{16,18,21}$. Admittedly, the experimental and modeling approaches used in this study involve simplification of the immense biological, chemical, and physical complexities found in soil that operate over a range of time scales to bring about bacterial community response and organization. Nevertheless, consideration of some of the simplest attributes of soil pore spaces offer useful building blocks for improved understanding of ingredients important for bacterial community functioning in soil. Clearly, further efforts are required to address the temporal dynamics of soil bacterial organization and activity in response to changes in chemical boundary conditions induced by desaturation or similar processes. Platforms combining experimental and individual-based 
Table 1 Parameters used in the mathematical model and their source reference

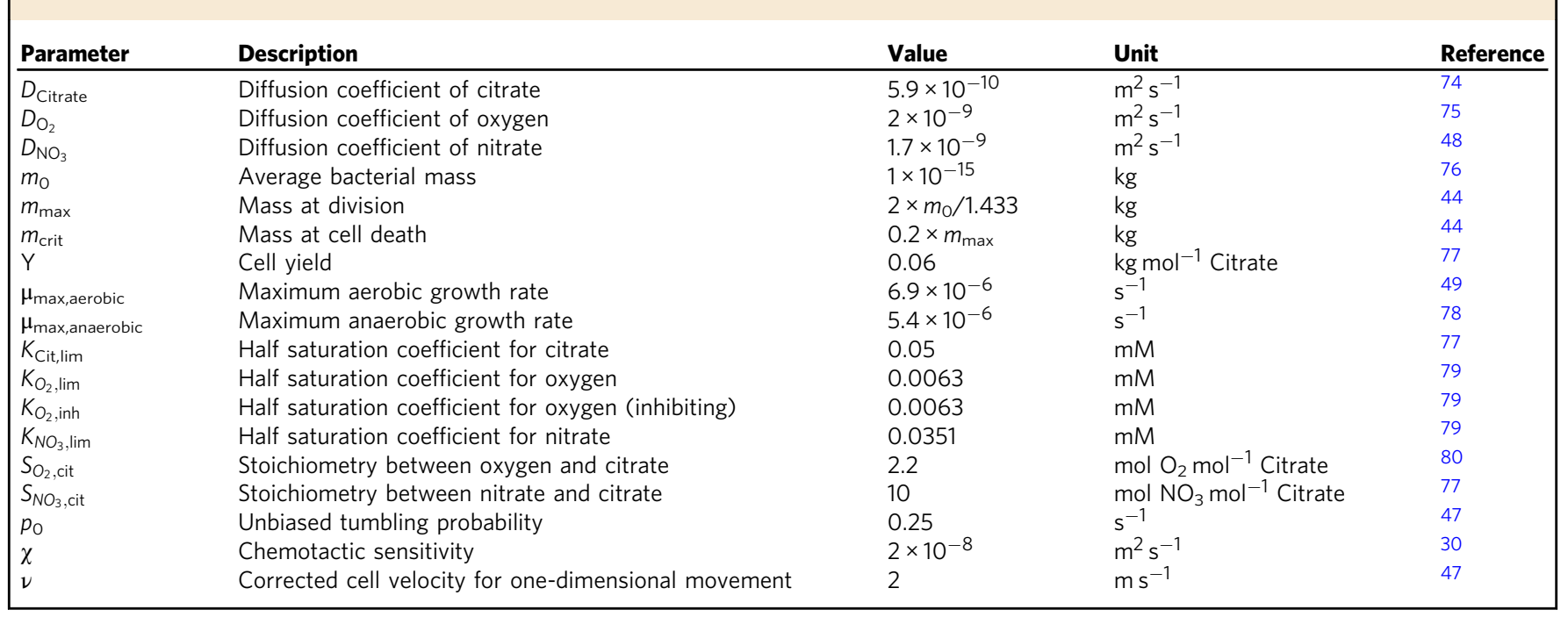

models, with controlled boundary conditions while enabling visualization of the response of tagged bacterial populations, offer a promising tool to further reveal the mechanics and dynamics of bacterial organization and function in microhabitats.

\section{Methods}

Bacterial strains and culture conditions. Pseudomonas putida KT2440 (strict aerobe) $^{65}$ and Pseudomonas veronii 1YdBTEX2 (facultative anaerobe) ${ }^{66}$ are chromosomally tagged with a mini-Tn7 transposon ${ }^{67}$ conferring resistance to gentamycin and expressing the enhanced green fluorescent protein (eGFP) or the mCherry fluorescent protein, respectively, under control of a constitutively active Plac-derivative promoter. Strain KT2440-gfp was a gift from Arnaud Dechesne (Department of Environmental Engineering, Technical University of Denmark) and is described in more detail in ref. ${ }^{67}$. Strain 1YdBTEX2-mChe was a gift from Jan Roelof van der Meer (Department of Fundamental Microbiology, University of Lausanne); the mini-Tn7-mCherry genetic construct used to tag strain 1YdBTEX2 is described in more detail in ref. ${ }^{68}$. Both tagged strains were routinely grown in shaken Luria-Bertani (LB) liquid culture or on LB agar plates at $30^{\circ} \mathrm{C}$ with $10 \mu \mathrm{g} /$ $\mathrm{mL}$ gentamycin.

As a minimal medium, we used modified M9 $\left(90.2 \mathrm{mM} \mathrm{Na} \mathrm{HPO}_{4}, 8.6 \mathrm{mM}\right.$ $\mathrm{NaCl}, 18.7 \mathrm{mM} \mathrm{NH}_{4} \mathrm{Cl}, 14.7 \mathrm{mM} \mathrm{KH}_{2} \mathrm{PO}_{4}, 15.1 \mathrm{mM}$ L-asparagine, $2 \mathrm{mM} \mathrm{MgSO}_{4}$, $0.1 \mathrm{mM} \mathrm{CaCl}_{2}, 0.1 \mathrm{mM} \mathrm{FeCl} \cdot 6 \mathrm{H}_{2} \mathrm{O}, 10 \mu \mathrm{g} / \mathrm{mL}$ gentamycin). Additionally, liquid media were supplemented with trace metals $\left(\approx 1 \mu \mathrm{M}\right.$ of $\mathrm{CuCl}_{2}, \mathrm{ZnSO}_{4}, \mathrm{MnCl}_{2}$, $\mathrm{ZnSO}_{4}, \mathrm{CoCl}_{2}, \mathrm{NiSO}_{4}$, and $\mathrm{Na}_{2} \mathrm{MoO}_{4}$ ). When required, for example, for overnight cultures or experiments in shaken flasks, media were supplemented with $10 \mathrm{mM}$ $\mathrm{Na}_{3}$ Citrate and $10 \mathrm{mM} \mathrm{NaNO}$.

Pore networks design. Glass-etched micrometric pore networks were manufactured by Micronit Microtechnologies (Enschede, The Netherlands). Pore networks were designed in Mathematica by creating a fully connected, hexagonal lattice with the desired channel length $(200 \mu \mathrm{m})$ and subsequently randomly deleting the required percentage of all bonds (30\% of all bonds for the $70 \%$ lattice and $60 \%$ of all bonds for the $40 \%$ lattice) to obtain the reduced connectivity lattice. Compared to other pore network designs which use geometries based on CT images ${ }^{63}$, our choice of simple geometry enables us to relate observed spatial patterns directly to the diffusional properties of the networks as these can be calculated with ease. Finally, percolation of the network was tested (i.e., ensuring a bacterial cell can move to any point within the network from any location). CAD files were then sent to Micronit Microtechnologies for the creation of the desired micrometric networks through isotropic wet etching. Each channel has dimensions of $200 \mu \mathrm{m} \times 40 \mu \mathrm{m} \times 15 \mu \mathrm{m}(L \times W \times H)$, which allows ample space for bacterial flagellated motility ${ }^{47,69}$.

Bacterial spatial organization in pore networks. Glass-etched micrometric pore networks were saturated with modified M9 media devoid of citrate using a vacuum desiccator ( $12 \mathrm{~h}$ at 0.1 bar). The choice of saturation method resulted in initially microaerobic conditions within the pore network due to the applied vacuum (Supplementary Fig. 2). Overnight cultures of strains KT2440-gfp and 1YdBTEX2mChe in minimal medium supplemented with citrate and nitrate were diluted in the same medium to obtain an optical density at $600 \mathrm{~nm}\left(\mathrm{OD}_{600}\right)$ of 0.01 , after which they were mixed at a 1:1 ratio to serve as an inoculation community. One microliter of the inoculation community (approximately 1,000 cells in total) was subsequently pipetted into the central port filling the port itself. After $30 \mathrm{~min}$ of allowing bacterial cells to enter the network, $5 \mu \mathrm{L}$ molten $1.4 \%$ M9 agar (approximately double the total pore volume) containing $100 \mathrm{mM}$ citrate and nitrate was pipetted into the central port as a primary carbon and energy source. After a further $60 \mathrm{~min}$, flowable silicone (Elastosil E41) was used to cover the solidified agar and thereby restrict oxygen diffusing into the pore network center. At the four peripheral ports filled with liquid growth media, oxygen was able to diffuse into the pore network following Henry's law with atmospheric oxygen above the ports. The inoculated lattice was incubated inside a $50 \mathrm{ml}$ Falcon tube (representing a wet chamber to suppress evaporation) for 7 days at room temperature $\left(\sim 23^{\circ} \mathrm{C}\right)$ to allow for bacterial growth and spatial organization.

Image acquisition and digital image analysis. Prior to image acquisition, the micrometric pore networks were taken out of the incubation chamber, then the agar plug on the central port was removed, and the port was left open for $30 \mathrm{~min}$ This ensured that oxygen was available in the center of the pore network (oxygen is necessary for the maturation of autofluorescent proteins and hence good fluorescent signal). By observing the cell distribution during this oxygenation period, it was ensured that no reorganization of the population was occurring due to the enhanced oxygen availability at the central port. Images of fluorescent bacteria in the pore networks were obtained with a DM6000B epifluorescence microscope (Leica Microsystems, Heerbrugg, Switzerland) using a 40×/0.60 HC PL Fluotar objective (Leica Microsystems). We sequentially recorded phase contrast images and fluorescence images with a DFC350 FX camera (Leica Microsystems) using an L5 filter cube for eGFP (exciter: 480/40; emitter: 527/30: beamsplitter: 505) and a Y3 filter cube for mCherry (exciter: 545/25; emitter: 605/70: beamsplitter: 565 ) (Leica Microsystems). Exposure time, gain value, and illumination intensity were optimized independently for eGFP and mCherry signals, with a Gamma function set to 1. The Leica Application Suite (LAS) acquisition software (Leica Microsystems) was used to acquire multiple fields of view and to assemble them into a composite image with the tile scan function of the LAS software. Overlay images of eGFP and mCherry fluorescence were shown with the pseudo-colors cyan and magenta, respectively.

Digital image analysis was performed using the KNIME Analytics platform version 3.2.1 (KNIME.COM AG, Zürich, Switzerland) including the KNIME Image Processing toolbox (KNIP) version 1.5.2. eGFP and mCherry fluorescent images were separately exported from the Leica Application Suite software as tiff files and subsequently loaded into KNIME. The images were binarized using the Triangle threshold method ${ }^{70}$. A morphological operation (open, four connected) was performed to erase tiny bright spots too small to be counted as bacterial cells. A connected-component analysis (four connected) yielded individual areas identified as bacterial cell mass. Individual areas with a size smaller than 5 pixels or larger than 1,000 (approximately $0.1 \%$ of the image size) were neglected. Each identified bacterial cell was divided by the median cell pixel size to account for areas representing more than one cell (i.e., overlapping or touching cells). Ratios $<1$ were counted as one bacterial cell while for ratios larger than one the decimal value was taken. In order to calculate the shortest path distance from the center to the cell location, identified bacteria were mapped onto the network using Matlab version R2016b (Mathworks, Natick, MA, USA). Phase contrast tile scans were used to recover the homography using 12 pass points. Bacterial cells were then attributed to the closest node of the pore network. Cells mapped within a radius of $0.5 \mathrm{~mm}$ of a port were neglected, as port wall reflections created artifacts within close proximity of the port. Finally, a histogram of bacterial cells along the shortest path from the 
center to the node location was created using 20 histogram bins to obtain an average cell number per node.

Confirmation of anoxia and oxygen gradients. An oxygen optode (PreSens VisiSens A1 Detector unit and AnalytiCal 1 Software, PreSens Precision Sensing $\mathrm{GmbH}$, Regensburg, Germany) was used to assess oxygen levels at the center of the pore network and peripheral ports. This was done by including an SF-RPSu4 oxygen sensor foil on top of the central port before adding nutrient-rich agar and flowable silicone to measure oxygen levels at the center. At the peripheral ports, the same oxygen sensor foil was brought into contact with growth media inside the port (atmospheric oxygen). Oxygen levels were observed after 7 days of incubation at room temperature $\left(\sim 23^{\circ} \mathrm{C}\right)$. The importance of bacterial activity for maintaining the oxygen gradients was assessed by comparing two lattices, where one was inoculated with the standard model community (1:1 ratio of aerobes to anaerobes) while the other was left sterile.

Experiments in unstructured and homogeneous environment. Overnight cultures of both aerobes and anaerobes in $5 \mathrm{~mL}$ modified M9 minimal media were diluted to an $\mathrm{OD}_{600}$ of 1 . The two species were mixed at a 1:1 ratio as an inoculation community having an equal abundance. Ten microliters of this community were subsequently inoculated into $10 \mathrm{~mL}$ of modified M9 medium containing 10 $\mathrm{mM}$ citrate and $10 \mathrm{mM}$ nitrate in a test tube (for aerobic growth) or sealed serum flasks (for anaerobic growth). Ten replicate cultures were used for both the aerobic and anaerobic case. Bacterial cocultures were then incubated with shaking at 280 $\mathrm{rpm}$ and $30^{\circ} \mathrm{C}$ for $48 \mathrm{~h}$. Samples were diluted down to an $\mathrm{OD}_{600}$ of 0.1 (approximately $5 \times 10^{7}$ cells per $\mathrm{mL}$ ). The cultures were then further diluted by a factor of $10^{4}$ before plating $20 \mu \mathrm{L}$ onto LB agar containing $10 \mu \mathrm{g} / \mathrm{mL}$ gentamycin. Three plates from each flask/test tube were created. Agar plates were incubated for $48 \mathrm{~h}$ at $30^{\circ} \mathrm{C}$ and subsequently stored at $4{ }^{\circ} \mathrm{C}$ for a further $24 \mathrm{~h}$ to allow the accumulation of fluorescent proteins before counting the number of colonyforming units per species.

Mathematical model description. The mathematical model consists of a combination of numerical nutrient diffusion with an individual representation of bacterial cells. Chemical diffusion is simulated as a one-dimensional diffusive process following Fick's law between two nodes/junctions while respecting mass balance at a node as described by Eq. 1 , where $C$ is the substrate concentration, $t$ is time, $J$ are the fluxes between nodes, and $R$ is bacterial consumption

$$
\frac{\partial C}{\partial t}=\sum J-R
$$

The equation is numerically approximated using an implicit scheme. Neumann and Dirichlet boundary conditions are represented using mirror nodes. Total bacterial consumption at one node is calculated as the sum of consumption from cells residing at the respective node.

Bacterial growth is simulated using Monod kinetics and relating biomass production to substrate consumption by stoichiometry. Although Monod's equation describes the growth of a bacterial population, it has been used frequently to relate growth of individual cells to local nutrient concentrations within individual-based models ${ }^{44,49,71-73}$. Change in bacterial mass for each cell is calculated by Eq. 2, where $m_{\mathrm{b}}$ is the cell mass of bacterial cell b, $\mu_{j}$ the growth rate calculated at node $j$ for the respective species, and $\mu_{\text {maint }}$ the cell maintenance taken as $10 \%$ of the maximum growth rate ${ }^{48}$. Carbon is consumed by both species according to the specific yield. Additionally, aerobes consume oxygen and anaerobes consume nitrate at ratios given by the respective stoichiometry (see Table 1 for parameter values). For aerobic cells, carbon limitation and oxygen limitation terms are included in the growth rate calculation, while carbon limitation, oxygen inhibition, and nitrate limitation terms are included for the anaerobic species as shown by Eqs. 3 and 4 , respectively. Here, $\mu_{\max }$ is the maximum specific growth rate, $C_{n}$ the concentration of substrate $n, K_{n}$ lim the limitation coefficient of substrate $n$, and $K_{n \text {,inh }}$ the inhibition coefficient of substrate

$$
\begin{gathered}
\frac{\partial m_{b}}{\partial t}=\left(\mu_{j}-\mu_{\text {maint }}\right) * m_{b}, \\
\mu_{\text {aerobe }}=\mu_{\text {max,aerobe }} * \min \left(\frac{C_{\mathrm{C}}}{K_{\mathrm{C}, \mathrm{lim}}+C_{\mathrm{C}}}, \frac{C_{\mathrm{O}_{2}}}{K_{\mathrm{O}_{2}, \lim }+C_{\mathrm{O}_{2}}}\right), \\
\mu_{\text {anaerobe }}=\mu_{\text {max }, \text { anaerobe }} * \min \left(\frac{C_{\mathrm{C}}}{K_{\mathrm{C}, \text { lim }}+C_{\mathrm{C}}}, \frac{K_{\mathrm{O}_{2}, \text { inh }}}{K_{\mathrm{O}_{2}, \text { inh }}+C_{\mathrm{O}_{2}}}, \frac{C_{\mathrm{NO}_{3}}}{K_{\mathrm{NO}_{3}, \lim }+C_{\mathrm{NO}_{3}}}\right) .
\end{gathered}
$$

Cells can divide if reaching a mass at division where all properties are inherited and cell mass is divided approximately equally. Cells die if their mass reaches a critical value and are removed from the simulation.
Bacterial motility is simulated as a biased run-and-tumble mechanism ${ }^{47}$ including chemotaxis towards multiple nutrient and oxygen sources ${ }^{30}$. In each iteration, the probability of tumbling for individual cells is calculated by Eq. 5 , where $p$ is the tumbling probability, $p_{0}$ is the tumbling probability in the absence of chemical attractors or repellents, $\chi$ is chemotactic sensitivity, $v$ the cell swimming velocity, $\mu_{\max }$ the maximum growth rate of the species, and $\Delta \mu / \Delta x$ the growth rate gradient with respect to the change in cell position. The calculated tumbling probability is then used to determine if the cell tumbles or not. If tumbling within a channel, there is a $50 \%$ probability to revert direction. Having reached a junction, bacterial cells are forced to tumble where a new direction is chosen at random from all connected channels

$$
p=p_{0} \mathrm{e}^{-\frac{\chi \Delta \mu}{2 v \mu_{\max } \Delta x}}
$$

Subsequently, bacterial cells move in a straight line at a constant velocity along a channel simulating a run. Therefore, the change in bacterial cell position is calculated by Eq. 6 , where $\boldsymbol{X}$ is the position vector in two dimensional Euclidean space at time point $t$ or $t+1, \mathbf{v}$ the cell velocity vector in direction of the channel, and $\Delta t$ the time step

$$
\mathbf{X}_{t+1}=\mathbf{X}_{t}+\mathbf{v} * \Delta t
$$

Within each time step, the model first calculates chemical diffusion of substrates and consumption from the previous time step, bacterial motility, growth of bacterial cells, and new consumption, and finally checks for cell division and cell death.

Model parameters and boundary conditions. Congruent to the experimental protocol, bacterial cells were inoculated at the central port combined with a constant carbon and nitrate source. A constant concentration boundary of $10 \mathrm{mM}$ citrate and nitrate was applied. Oxygen was supplied from the peripheral ports by keeping a constant concentration determined by Henry's law $(0.27 \mathrm{mM})$. Bacterial consumption represents the only sink for nutrients within the network (i.e., no physical sinks). Different ratios of aerobes to anaerobes and total combined cell numbers were simulated for each network topology. The different initial population ratios, where the first number represents introduced aerobic cells and the second anaerobic cells, were $1,000 \times 1,000,500 \times 500,100 \times 100,1 \times 1,500 \times 100$, $100 \times 500,1000 \times 1$, and $1 \times 1,000$. The total simulated time was 7 days at $10 \mathrm{~s}$ time steps. All parameters of the model are obtained from literature (see Table 1 below for the original references) and are thus independent from the experiments.

Code availability. Computer code used within this study is available from the corresponding author upon reasonable request.

Data availability. The experimental and simulation data that support the findings of this study are available from the corresponding author upon reasonable request $\mathrm{CAD}$ files containing the full description of the micrometric pore networks are available upon request.

Received: 29 May 2017 Accepted: 26 January 2018 Published online: 22 February 2018

\section{References}

1. Torsvik, V., Goksoyr, J. \& Daae, F. L. High diversity in DNA of soil bacteria. Appl. Environ. Microbiol. 56, 782-787 (1990).

2. Curtis, T. P., Sloan, W. T. \& Scannell, J. W. Estimating prokaryotic diversity and its limits. Proc. Natl. Acad. Sci. USA 99, 10494-10499 (2002).

3. Falkowski, P. G., Fenchel, T. \& Delong, E. F. The microbial engines that drive Earth's biogeochemical cycles. Science 320, 1034-1039 (2008).

4. Tecon, R. \& Or, D. Biophysical processes supporting the diversity of microbial life in soil. FEMS Microbiol. Rev. 41, 599-623 (2017).

5. Kuzyakov, Y. \& Blagodatskaya, E. Microbial hotspots and hot moments in soil: concept \& review. Soil Biol. Biochem. 83, 184-199 (2015).

6. Jones, D. L., Hodge, A. \& Kuzyakov, Y. Plant and mycorrhizal regulation of rhizodeposition. New Phytol. 163, 459-480 (2004).

7. Hinsinger, P., Bengough, A. G., Vetterlein, D. \& Young, I. M. Rhizosphere: biophysics, biogeochemistry and ecological relevance. Plant Soil 321, 117-152 (2009).

8. Kögel-Knabner, I. The macromolecular organic composition of plant and microbial residues as inputs to soil organic matter. Soil Biol. Biochem. 34, 139-162 (2002).

9. Tiunov, A. V. \& Scheu, S. Microbial respiration, biomass, biovolume and nutrient status in burrow walls of Lumbricus terrestris L. (Lumbricidae). Soil Biol. Biochem. 31, 2039-2048 (1999). 
10. Tiunov, A. V. \& Scheu, S. Carbon availability controls the growth of detritivores (Lumbricidae) and their effect on nitrogen mineralization Oecologia 138, 83-90 (2004).

11. Schrader, S., Rogasik, H., Onasch, I. \& Jégou, D. Assessment of soil structural differentiation around earthworm burrows by means of X-ray computed tomography and scanning electron microscopy. Geoderma 137, 378-387 (2007).

12. Tisdall, J. M. \& Oades, J. M. Organic matter and water-stable aggregates in soils. J. Soil Sci. 33, 141-163 (1982).

13. Six, J., Elliott, E. T. \& Paustian, K. Soil macroaggregate turnover and microaggregate formation: a mechanism for $\mathrm{C}$ sequestration under no-tillage agriculture. Soil Biol. Biochem. 32, 2099-2103 (2000).

14. Six, J., Bossuyt, H., Degryze, S. \& Denef, K. A history of research on the link between (micro)aggregates, soil biota, and soil organic matter dynamics. Soil Tillage Res. 79, 7-31 (2004).

15. Parkin, T. B. Soil microsites as a source of denitrification variability. Soil Sci. Soc. Am. J. 51, 1194-1199 (1987).

16. Sexstone, A. J., Revsbech, N. P., Parkin, T. B. \& Tiedje, J. M. Direct measurement of oxygen profiles and denitrification rates in soil aggregates. Soil Sci. Soc. Am. J. 49, 645-651 (1985).

17. Uteau, D. et al. Oxygen and redox potential gradients in the rhizosphere of alfalfa grown on a loamy soil. J. Plant Nutr. Soil Sci. 178, 278-287 (2015).

18. Philippot, L. et al. Dissimilatory nitrite-reductase provides a competitive advantage to Pseudomonas sp. RTC01 to colonise the centre of soil aggregates. FEMS Microbiol. Ecol. 21, 175-185 (1996).

19. Tiedje Sexstone, A. J., Parkin, T. B. \& Revsbech, N. P. Anaerobic processes in soil. Plant Soil 76, 197-212 (1984).

20. Angel, R., Claus, P. \& Conrad, R. Methanogenic archaea are globally ubiquitous in aerated soils and become active under wet anoxic conditions. ISME J. 6, 847-862 (2012).

21. Højberg, O., Revsbech, N. P. \& Tiedje, J. M. Denitrification in soil aggregates analyzed with microsensors for nitrous oxide and oxygen. Soil Sci. Soc. Am. J. 58, 1691-1698 (1994).

22. Peth, $\mathrm{S}$. et al. Localization of soil organic matter in soil aggregates using synchrotron-based X-ray microtomography. Soil Biol. Biochem. 78, 189-194 (2014).

23. Ruamps, L. S. et al. Regulation of soil organic C mineralisation at the pore scale. FEMS Microbiol. Ecol. 86, 26-35 (2013).

24. Chenu, C., Hassink, J. \& Bloem, J. Short-term changes in the spatial distribution of microorganisms in soil aggregates as affected by glucose addition. Biol. Fertil. Soils 34, 349-356 (2001).

25. Ruamps, L. S., Nunan, N. \& Chenu, C. Microbial biogeography at the soil pore scale. Soil Biol. Biochem. 43, 280-286 (2011).

26. Fuhrman, J. A. Microbial community structure and its functional implications. Nature 459, 193-199 (2009).

27. Nadell, C. D., Foster, K. R. \& Xavier, J. B. Emergence of spatial structure in cell groups and the evolution of cooperation. PLoS Comput. Biol. 6, e1000716 (2010).

28. Wang, G. \& Or, D. Trophic interactions induce spatial self-organization of microbial consortia on rough surfaces. Sci. Rep. 4, 6757 (2014).

29. Kaiser, C., Franklin, O., Richter, A. \& Dieckmann, U. Social dynamics within decomposer communities lead to nitrogen retention and organic matter buildup in soils. Nat. Commun. 6, 8960 (2015).

30. Kim, M. \& Or, D. Individual-based model of microbial life on hydrated rough soil surfaces. PLoS ONE 11, e0147394 (2016).

31. Nishio, M. \& Furusaka, C. The distribution of nitrifying bacteria in soil aggregates. Soil Sci. Plant Nutr. 16, 24-29 (1970).

32. Momeni, B., Waite, A. J. \& Shou, W. Spatial self-organization favors heterotypic cooperation over cheating. Elife 2, e00960 (2013).

33. Mitri, S., Clarke, E. \& Foster, K. R. Resource limitation drives spatial organization in microbial groups. ISME J. 10, 1-12 (2015).

34. Ratzke, C. \& Gore, J. Self-organized patchiness facilitates survival in a cooperatively growing Bacillus subtilis population. Nat. Microbiol. 1, 16022 (2016).

35. Tecon, R. \& Or, D. Cooperation in carbon source degradation shapes spatial self-organization of microbial consortia on hydrated surfaces. Sci. Rep. 7, 43726 (2017).

36. Camazine, S. et al. Self-Organization in Biological Systems (Princeton University Press, Princeton, USA, 2001).

37. Wang, G. \& Or, D. Hydration dynamics promote bacterial coexistence on rough surfaces. ISME J. 7, 395-404 (2013).

38. Ananyeva, K., Wang, W., Smucker, A. J. M., Rivers, M. L. \& Kravchenko, A. N. Can intra-aggregate pore structures affect the aggregate's effectiveness in protecting carbon? Soil Biol. Biochem. 57, 868-875 (2013).

39. Kravchenko, A. N. et al. Intra-aggregate pore structure influences phylogenetic composition of bacterial community in macroaggregates. Soil Sci. Soc. Am. J. 78, 1924-1939 (2014).
40. Nunan, N., Wu, K., Young, I. M., Crawford, J. W. \& Ritz, K. Spatial distribution of bacterial communities and their relationships with the microarchitecture of soil. FEMS Microbiol. Ecol. 44, 203-215 (2003).

41. Young, I. M. \& Crawford, J. W. Interactions and self-organization in the soil-microbe complex. Science 304, 1634-1637 (2004).

42. Mummey, D. L. \& Stahl, P. D. Analysis of soil whole- and innermicroaggregate bacterial communities. Microb. Ecol. 48, 41-50 (2004).

43. Mummey, D., Holben, W., Six, J. \& Stahl, P. Spatial stratification of soil bacterial populations in aggregates of diverse soils. Microb. Ecol. 51, 404-411 (2006).

44. Kreft, J. U., Booth, G. \& Wimpenny, J. W. T. BacSim, a simulator for individual-based modelling of bacterial colony growth. Microbiology 144, 3275-3287 (1998)

45. Kreft, J. U. et al. Mighty small: observing and modeling individual microbes becomes big science. Proc. Natl. Acad. Sci. USA 110, 18027-18028 (2013).

46. Hellweger, F. L., Clegg, R. J., Clark, J. R., Plugge, C. M. \& Kreft, J. U. Advancing microbial sciences by individual-based modelling. Nat. Rev. Microbiol. 14, 461-471 (2016).

47. Berg, H. C. \& Brown, D. A. Chemotaxis in Escherichia coli analysed by threedimensional tracking. Nature 239, 500-504 (1972).

48. Kreft, J. U., Picioreanu, C., Wimpenny, J. W. T. \& Van Loosdrecht, M. C. M. Individual-based modelling of biofilms. Microbiology 147, 2897-2912 (2001).

49. Lardon, L. A. et al. iDynoMiCS: next-generation individual-based modelling of biofilms. Environ. Microbiol. 13, 2416-2434 (2011).

50. Ebrahimi, A. N. \& Or, D. Microbial dispersal in unsaturated porous media: characteristics of motile bacterial cell motions in unsaturated angular pore networks. Water Resour. Res. 50, 7406-7429 (2014).

51. Klimant, I., Kühl, M., Glud, R. N. \& Holst, G. Optical measurement of oxygen and temperature in microscale: strategies and biological applications. Sens. Actuators B Chem. 38, 29-37 (1997).

52. Glud, R. N. et al. An in situ instrument for planar $\mathrm{O}_{2}$ optode measurements at benthic interfaces. Limnol. Oceanogr. 46, 2073-2080 (2001).

53. Ebrahimi, A. \& Or, D. Hydration and diffusion processes shape microbial community organization and function in model soil aggregates. Water Resour. Res. 51, 9804-9827 (2015).

54. Kuzyakov, Y. \& Domanski, G. Carbon input by plants into the soil. Review. J. Plant Nutr. Soil Sci. 163, 421-431 (2000).

55. Alldredge, A. L. \& Cohen, Y. Can microscale chemical patches persist in the sea? Microelectrode study of marine snow, fecal pellets. Science 235, 689-691 (1987).

56. Odling-Smee, F. J., Laland, K. N. \& Feldman, M. W. Niche construction. Am. Nat. 147, 641 (1996).

57. Kim, H. J., Boedicker, J. Q., Choi, J. W. \& Ismagilov, R. F. Defined spatial structure stabilizes a synthetic multispecies bacterial community. Proc. Natl. Acad. Sci. USA 105, 18188-18193 (2008).

58. Harwood, C. S., Fosnaugh, K. \& Dispensa, M. Flagellation of Pseudomonas putida and analysis of its motile behavior. J. Bacteriol. 171, 4063-4066 (1989).

59. Nichols, N. N. \& Harwood, C. S. An aerotaxis transducer gene from Pseudomonas putida. FEMS Microbiol. Lett. 182, 177-183 (2000).

60. Elomari, M. et al. DNA relatedness among Pseudomonas strains isolated from natural mineral waters and proposal of Pseudomonas veronii sp. nov. Int. J. Syst. Bacteriol. 46, 1138-1144 (1996).

61. Coyte, K. Z., Tabuteau, H., Gaffney, E. A., Foster, K. R. \& Durham, W. M. Microbial competition in porous environments can select against rapid biofilm growth. Proc. Natl. Acad. Sci. USA 114, 161-170 (2017).

62. Or, D., Phutane, S. \& Dechesne, A. Extracellular polymeric substances affecting pore-scale hydrologic conditions for bacterial activity in unsaturated soils. Vadose Zone J. 6, 298 (2007).

63. Deng, J. et al. Synergistic effects of soil microstructure and bacterial EPS on drying rate in emulated soil micromodels. Soil Biol. Biochem. 83, 116-124 (2015).

64. Ebrahimi, A. \& Or, D. Microbial community dynamics in soil aggregates shape biogeochemical gas fluxes from soil profiles-upscaling an aggregate biophysical model. Glob. Change Biol. 22, 3141-3156 (2016).

65. Belda, E. et al. The revisited genome of Pseudomonas putida KT2440 enlightens its value as a robust metabolic chassis. Environ. Microbiol. 18, 3403-3424 (2016).

66. de Lima-Morales, D. et al. Draft genome sequence of Pseudomonas veronii strain 1YdBTEX2. Genome Announc. 1, https://doi.org/10.1128/ genomeA.00258-13 (2013).

67. Lambertsen, L., Sternberg, C. \& Molin, S. Mini-Tn7 transposons for sitespecific tagging of bacteria with fluorescent proteins. Environ. Microbiol. 6, 726-732 (2004).

68. Tecon, R., Binggeli, O. \& Van Der Meer, J. R. Double-tagged fluorescent bacterial bioreporter for the study of polycyclic aromatic hydrocarbon diffusion and bioavailability. Environ. Microbiol. 11, 2271-2283 (2009). 
69. Or, D., Smets, B. F., Wraith, J. M., Dechesne, A. \& Friedman, S. P. Physica constraints affecting bacterial habitats and activity in unsaturated porous media-a review. Adv. Water Resour. 30, 1505-1527 (2007).

70. Zack, G. W. \& Rogers, E. Automatic measurement of sister chromatid exchange frequency. J. Histochem. Cytochem. 25, 11-14 (1977).

71. Kreft, J. U. \& Wimpenny, J. W. T. Effect of EPS on biofilm structure and function as revealed by an individual-based model of biofilm growth. Water Sci. Technol. 43, 135-141 (2001).

72. Kreft, J. U. Biofilms promote altruism. Microbiology 150, 2751-2760 (2004).

73. Martin, K. J., Picioreanu, C. \& Nerenberg, R. Multidimensional modeling of biofilm development and fluid dynamics in a hydrogen-based, membrane biofilm reactor (MBfR). Water Res. 47, 4739-4751 (2013).

74. Southard, M. Z., Dias, L. J., Himmelstein, K. J. \& Stella, V. J. Experimental determinations of diffusion coefficients in dilute aqueous solution using the method of hydrodynamic stability. Pharm. Res. 8, 1489-1494 (1991).

75. Han, P. \& Bartels, D. M. Temperature dependence of oxygen diffusion in $\mathrm{H}_{2} \mathrm{O}$ and $\mathrm{D}_{2}$ O. J. Phys. Chem. 100, 5597-5602 (1996).

76. Phillips, R., Kondev, J., Theriot, J., Garcia, H. \& Chasan, B. Physical biology of the cell. Am. J. Phys. 78, 1230 (2010).

77. Kornaros, M., Zafiri, C. \& Lyberatos, G. Kinetics of denitrification by Pseudomonas denitrificans under growth conditions limited by carbon and/or nitrate or nitrite. Water Environ. Res. 68, 934-945 (1996).

78. Kornaros, M. \& Lyberatos, G. Kinetics of aerobic growth of a denitrifying bacterium, Pseudomonas denitrificans, in the presence of nitrates and/or nitrites. Water Res. 31, 479-488 (1997).

79. Calderer, M., Jubany, I., Pérez, R., Martí, V. \& de Pablo, J. Modelling enhanced groundwater denitrification in batch micrococosm tests. Chem. Eng. J. 165, 2-9 (2010).

80. Kornaros, M. \& Lyberatos, G. Kinetic modelling of Pseudomonas dentrificans growth and denitrification under aerobic, anoxic and transient operating conditions. Water Res. 32, 1912-1922 (1998).

\section{Acknowledgements}

Financial support for this work came from an Advanced Grant to D.O. by the European Research Council (ERC-3200499-SoilLife) and from the RTD SystemsX.ch project MicroscapesX. We thank A. Dechesne (DTU) for the gift of P. putida KT2440-gfp and J.R. van der Meer (UNIL) for the gift of $P$. veronii 1YdBTEX2-mCherry. We are grateful to D. Johnson and J. Dolinsek (EAWAG) for advice on anaerobic growth conditions, to
P. Lehmann and O. Ilie (ETHZ) for their help in pore networks design, M. Lever (ETHZ) for the use of the epifluorescence microscope, and Stefan auf der Maur for drawing Figure 1.

\section{Author contributions}

B.B., R.T., and D.O. conceived the study and wrote the manuscript. B.B. performed the experiments, analyzed the data, and wrote the mathematical model.

\section{Additional information}

Supplementary Information accompanies this paper at https://doi.org/10.1038/s41467018-03187-y.

Competing interests: The authors declare no competing financial interests.

Reprints and permission information is available online at http://npg.nature.com/ reprintsandpermissions/

Publisher's note: Springer Nature remains neutral with regard to jurisdictional claims in published maps and institutional affiliations.

cc) (i) Open Access This article is licensed under a Creative Common Attribution 4.0 International License, which permits use, sharing, adaptation, distribution and reproduction in any medium or format, as long as you give appropriate credit to the original author(s) and the source, provide a link to the Creative Commons license, and indicate if changes were made. The images or other third party material in this article are included in the article's Creative Commons license, unless indicated otherwise in a credit line to the material. If material is not included in the article's Creative Commons license and your intended use is not permitted by statutory regulation or exceeds the permitted use, you will need to obtain permission directly from the copyright holder. To view a copy of this license, visit http://creativecommons.org/ licenses/by/4.0/.

(C) The Author(s) 2018 